\title{
Towards imaging the spatial distribution of geochemical heterogeneities and arsenic sources
}

Rolle, Massimo; Battistel, Maria; Onses, Felix; Mortensen, Rasmus; Fakhreddine, Sarah; Fendorf, Scott; Kitanidis, Peter K.; Harry Lee, Jonghyun

\section{Publication date:}

2018

Document Version

Publisher's PDF, also known as Version of record

Link back to DTU Orbit

Citation (APA):

Rolle, M., Battistel, M., Onses, F., Mortensen, R., Fakhreddine, S., Fendorf, S., Kitanidis, P. K., \& Harry Lee, J. (2018). Towards imaging the spatial distribution of geochemical heterogeneities and arsenic sources. Abstract from 7th international congress \& exhibition on arsenic in the environment,environmental arsenic in a changing world (AS2018), Beijing, China.

\section{General rights}

Copyright and moral rights for the publications made accessible in the public portal are retained by the authors and/or other copyright owners and it is a condition of accessing publications that users recognise and abide by the legal requirements associated with these rights.

- Users may download and print one copy of any publication from the public portal for the purpose of private study or research.

- You may not further distribute the material or use it for any profit-making activity or commercial gain

- You may freely distribute the URL identifying the publication in the public portal 


\title{
Towards imaging the spatial distribution of geochemical heterogeneities and arsenic sources
}

\author{
Massimo Rolle ${ }^{1,2}$ \\ ${ }^{1}$ Deparment of Environmental Engineering, Technical University of Denmark, Kongens Lyngby, Denmark \\ ${ }^{2}$ SDC University, Beijing, China \\ Maria Battistel ${ }^{1}$, Felix Onses ${ }^{1}$, Rasmus Mortensen ${ }^{2}$, Sarah Fakhreddine ${ }^{3}$, Scott Fendorf ${ }^{3}$, Peter \\ K. Kitanidis ${ }^{3}$, Jonghyun Harry Lee ${ }^{3,4}$ \\ ${ }^{3}$ Deparment of Civil and Environmental Engineering, Stanford University, CA 94305 Stanford, USA \\ ${ }^{4}$ Department of Environmental Engineering, University of Hawaii, HA 96822, Honolulu, USA
}

\begin{abstract}
We propose a methodology to image the spatial distribution of reactive minerals in the subsurface based on distributed sensor measurements of water quality parameters coupled with forward and inverse reactive transport modeling. We focus on kinetic oxidative dissolution of pyrite and As-bearing pyrite minerals and we illustrate the potential of the methodology in synthetic modeling applications at different scales, as well as in laboratory flow-through experiments in 1-D column setups and 2-D flow-through chambers.
\end{abstract}

\section{INTRODUCTION}

The spatial distribution of physical and chemical heterogeneities is critical in many subsurface applications. For instance, the location of reactive minerals is a primary factor controlling the fate and transport of organic and inorganic pollutants in groundwater. The latter include geogenic contamination causing the release of heavy metals and metalloids such as arsenic. A number of studies have focused on using hydrologic measurements and inverse modeling techniques to image physical heterogeneity and the spatial distribution of hydraulic conductivity. However, the applications of such approaches to water quality and reactive transport problems are rare.

In this study we focus on oxidation of pyrite and Asbearing pyrite. This process is of key importance in many natural settings as well as in engineering applications such as managed aquifer recharge.

\section{METHODS}

\subsection{Flow-through experiments}

We studied the oxidative dissolution of pyrite in different experimental setups, including batch systems, 1-D column setups and 2-D flow-through chambers. Measurements of water quality parameters such as $\mathrm{pH}$, dissolved oxygen, iron and sulfur were useful to formulate and constrain pyrite dissolution kinetics. In particular, spatially-distributed measurements of dissolved oxygen in the 1-D and 2-D setups were instrumental for imaging pyrite inclusions. Noninvasive optode sensors along the column setups and at different cross sections in the 2-D system allowed us to measure oxygen transport and consumption at high spatial resolution (2.5 $\mathrm{mm}$ spacing). A schematic illustration of the experimental setup with two pyrite inclusions is provided in Figure 1.

(a) True Pyrite Distribution

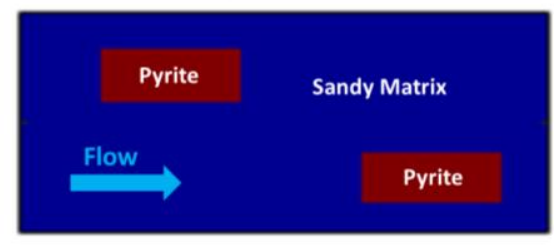

(b) Oxygen Concentration

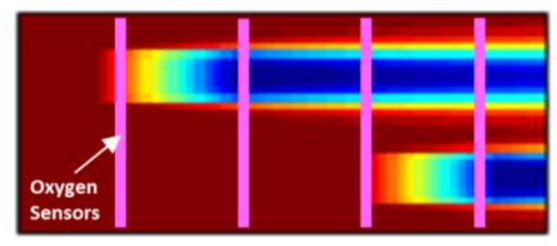

(c) Estimated Pyrite Distribution

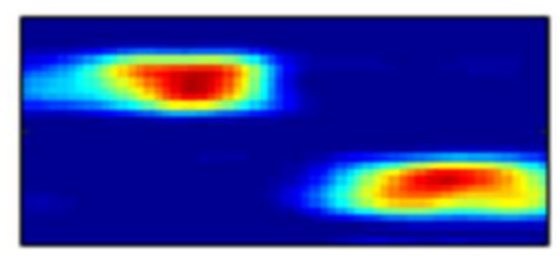

Figure 1. Schematic illustration of the 2-D experimental setup with two pyrite inclusions (a), location of distributed sensor measurements (b), and results of the inverse reactive transport simulations (c).

\subsection{Reactive transport modeling}

A reactive transport network, including the kinetics of pyrite and As-bearing pyrite oxidative dissolution, was implemented in PHT3D that served as the forward reactive transport simulator. The forward model was applied for synthetic simulations at different 
scales as well as to quantitatively interpret the laboratory results.

As inverse model, we used the Principal Component Geostatistical Approach (PCGA, Kitanidis and Lee, 2014) to determine the spatial distribution of pyrite and As-bearing pyrite. The PCGA approach was used in combination with the developed forward model and with a limited number of dissolved oxygen observations.

\section{RESULTS AND DISCUSSION}

The results of the laboratory experiments performed in a number of columns with different size, concentration and number of pyrite inclusions, as well as the outcomes of the 2-D flow-through experiments are presented by Battistel et al. (2017). Here we show some of the results of the synthetic applications at the field scale. Figure 2 a shows a 2-D cross section of a shallow aquifer with randomly distributed inclusions of As-bearing pyrite. The inversion was based on synthetic oxygen data, mimicking measurements in multilevel observation wells with 4 $\mathrm{m}$ spacing along the flow path. The results show the capability of the approach to correctly locate the Asbearing pyrite inclusions as well as their concentration. The outcomes show a good performance of the inversion also in presence of significant measurement errors (Figure $2 b$ and $2 c$ ).
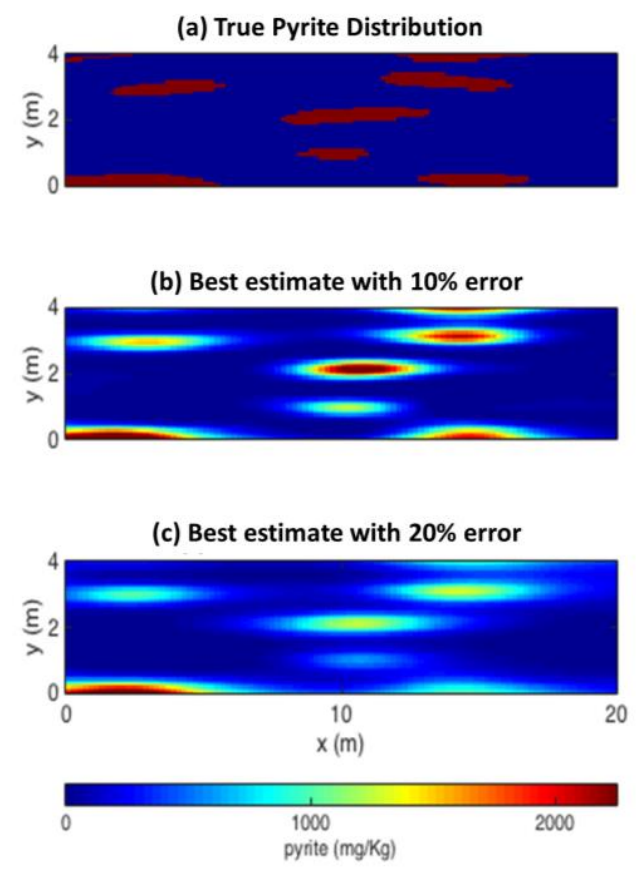

Figure 2. Maps of randomly distributed As-bearing pyrite: true distribution (a) and best estimate in case of $10 \%$ error (b) and $20 \%$ error (c) in DO measurement (modified from Fakhreddine et al., 2016).

Figure 3 shows the outcomes of simulations performed in the true geochemically heterogeneous aquifer as well as in the best estimate fields obtained with the proposed inverse method. The inverse results show the capability to reproduce the multiple plumes of dissolved arsenic in the heterogeneous domain. An increase in the oxygen measurement error still allows representing the main arsenic plumes, however, the small scale As-sources were more difficult to capture.

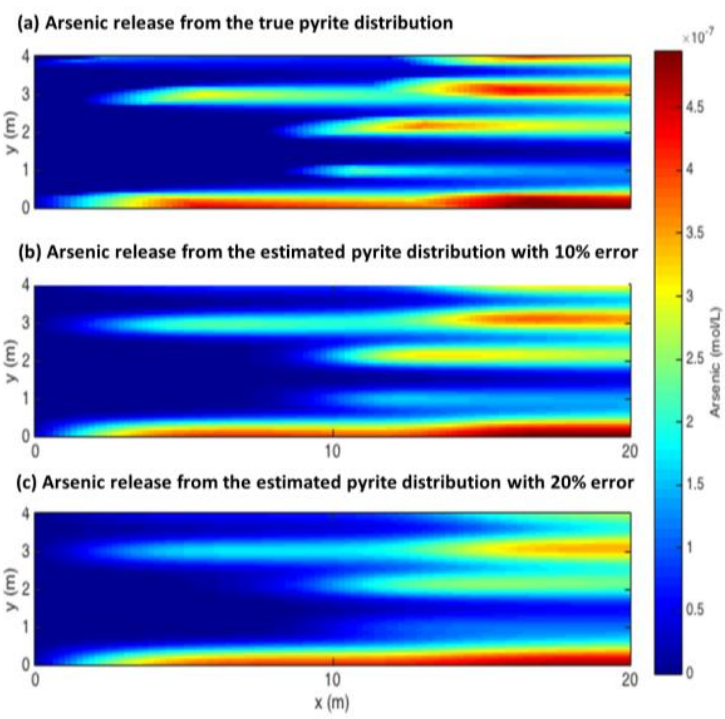

Figure 2. Arsenic plumes in the geochemically heterogeneous aquifers for the true As-bearing pyrite distribution (a), and for the best estimates ( $b$ and $c$ ) obtained with the proposed inverse modeling approach (modified from Fakhreddine et al., 2016).

\section{CONCLUSIONS}

We proposed an inverse method for tomography of geochemical heterogeneity. The investigation was focused on imaging the spatial distribution of pyrite and As-bearing pyrite based on spatially distributed oxygen measurements. The methodology proposed is flexible and can be extended to different processes, reactive minerals, as well as distributed measurements of other water quality parameters.

\section{ACKNOWLEDGEMENTS}

This study was supported by a grant from the Villum Foundation and by the Sino-Danish Center.

\section{REFERENCES}

Battistel, M., Lee, J., Onses, F., Mortensen, R. \& Rolle M. 2017. Imaging the spatial distribution of pyrite in porous media: multidimensional flow-through experiments and inverse modeling (in preparation).

Fakhreddine, S., Lee, J., Kitanidis, P.K., Fendorf, S. \& Rolle M. 2016. Imaging geochemical heterogeneity using inverse reactive transport modeling: An example for characterizing arsenic mobility and distribution. Adv. Water Resour., 88, 186-197.

Kitanidis, P.K \& Lee, J. 2014. Principal component geostatistical approach for large-dimensional inverse problems. Water Resour. Res., 50, 5428-5443. 